\title{
Methylation-related metabolic effects of D4 dopamine receptor expression and activation
}

\author{
Nathaniel W. Hodgson ${ }^{1}$, Mostafa I. Waly ${ }^{2}$, Malav S. Trivedi ${ }^{3}$, Verna-Ann Power-Charnitsky ${ }^{4}$ and Richard C. Deth $\mathbb{1}^{3}$
}

\begin{abstract}
D4 dopamine receptor (D4R) activation uniquely promotes methylation of plasma membrane phospholipids, utilizing folate-derived methyl groups provided by methionine synthase (MS). We evaluated the impact of D4R expression on folate-dependent phospholipid methylation (PLM) and MS activity, as well as cellular redox and methylation status, in transfected CHO cells expressing human D4R variants containing 2, 4, or 7 exon III repeats (D4.2R, D4.4R, D4.7R). Dopamine had no effect in non-transfected CHO cells, but increased PLM to a similar extent for both D4.2R- and D4.4R-expressing cells, while the maximal increase was for D4.7R was significantly lower. D4R expression in CHO cells decreased basal MS activity for all receptor subtypes and conferred dopamine-sensitive MS activity, which was greater with a higher number of repeats. Consistent with decreased MS activity, D4R expression decreased basal levels of methylation cycle intermediates methionine, S-adenosylmethionine (SAM), and S-adenosylhomocysteine (SAH), as well as cysteine and glutathione (GSH). Conversely, dopamine stimulation increased GSH, SAM, and the SAM/SAH ratio, which was associated with a more than 2-fold increase in global DNA methylation. Our findings illustrate a profound influence of D4R expression and activation on MS activity, coupled with the ability of dopamine to modulate cellular redox and methylation status. These previously unrecognized signaling activities of the D4R provide a unique link between neurotransmission and metabolism.
\end{abstract}

\section{Introduction}

Previous studies demonstrated the unique ability of D4 dopamine receptors (D4Rs) to carry out phospholipid methylation (PLM) in response to dopamine stimulation. ${ }^{1-4}$ PLM activity involves conformation-dependent methyl donation by a methionine side chain in the cytoplasmic extension of transmembrane helix \#6 (M313 in the D4.4R), in a cyclic process analogous to the welldescribed methionine-based methylation cycle (Fig. 1a). The D4R-mediated PLM cycle depends on replenishing methyl groups from 5-methyltetrahydrofolate (methylTHF) provided by methionine synthase (MS), and also requires methionine adenosyltransferase (MAT)

\footnotetext{
Correspondence: Richard C. Deth (rdeth@nova.edu)

${ }^{1}$ Department of Neurology and the F.M. Kirby Neurobiology Center, Boston Children's Hospital, Boston, MA 02115, USA

${ }^{2}$ Department of Food Science and Nutrition, College of Agricultural and Marine Sciences, Sultan Qaboos University, Muscat 123, Oman

Full list of author information is available at the end of the article.
}

and S-adenosylhomocysteine hydrolase $(\mathrm{SAHH}) .{ }^{1}$ As illustrated in Fig. 1a, MS transfers a methyl group from methylTHF to restore the D4R methionine residue (D4MET), in addition to its canonical role in converting free homocysteine (HCY) to methionine. These two competing reactions imply that D4R-mediated dopaminestimulated PLM activity could influence canonical Sadenosylmethionine (SAM)-dependent methionine cycle activity.

Cobalamin (vitamin $\mathrm{B}_{12}$ ), the cofactor for MS, is easily oxidized, ${ }^{5}$ making both $\mathrm{HCY}$ methylation and D4Rmediated PLM highly sensitive to oxidative stress. When MS activity decreases during oxidative stress, a greater proportion of $\mathrm{HCY}$ is converted to cysteine via transsulfuration, augmenting synthesis of the antioxidant glutathione (GSH) (Fig. 1a). Decreased MS activity also leads to depletion of SAM, the methyl donor for well over 200 different methylation reactions, including D4R-independent PLM and DNA methylation. 


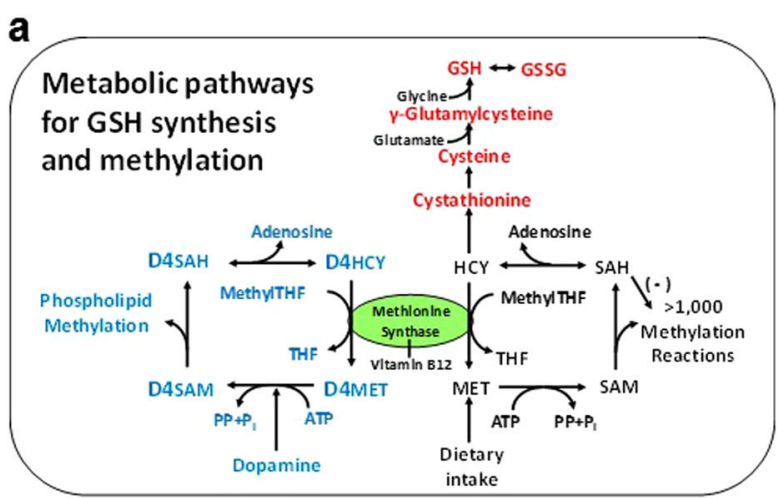

C

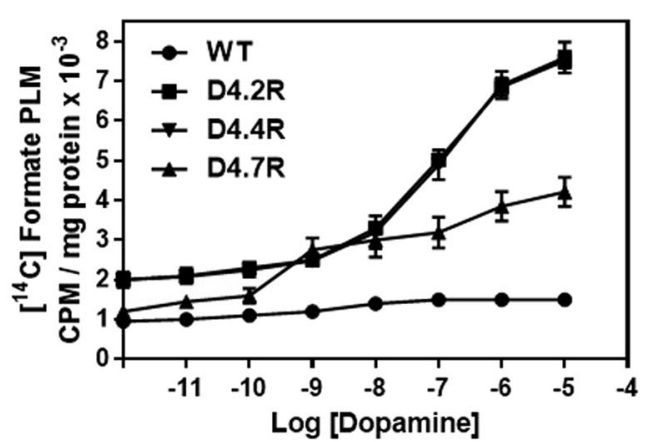

b

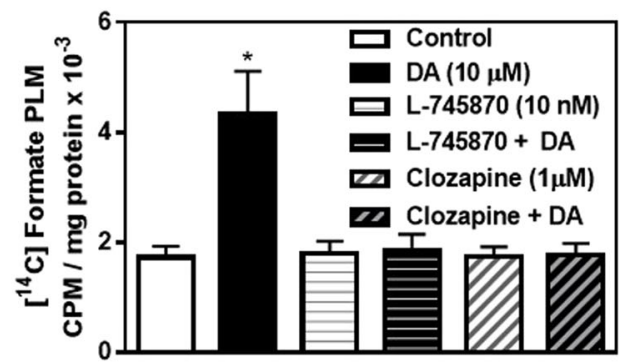

d

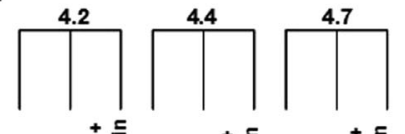

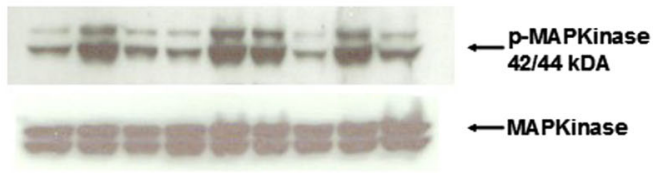

Fig. 1 Dopamine-stimulated PLM in D4R-expressing CHO cells. a The dopamine-stimulated D4R-mediated PLM cycle (lower left) functions in parallel to the canonical methionine cycle (lower right) and is completely dependent on MS activity and 5-methyltetrahydrofolate (methylTHF). Transsulfuration of homocysteine to cystathionine and cysteine supports GSH synthesis. b D4.4R-expressing CHO cells were treated with dopamine (DA) for 30 min with or without pretreatment with the highly D4R-selective antagonist L-745870 or the moderately selective D4R antagonist clozapine. Data are mean \pm SEM of two experiments $(n=6) .{ }^{*} p<0.05$ vs. Control. c Non-transfected CHO cells (WT) and CHO cells expressing D4.2R, D4.4R, and D4.7R were treated with graded concentrations of dopamine. Data are average $( \pm$ SEM) of two experiments $(n=6)$. (c) $(p<0.05)$. $\mathbf{d}$ CHO cells expressing D4.2R, D4.4R, or D4.7R were treated with dopamine $(10 \mu \mathrm{M} ; 30 \mathrm{~min})$ or dopamine + the PI3 kinase inhibitor wortmannin (100 nM; $60 \mathrm{~min}$ ). A Western blot was probed with anti-phospho-MAP kinase (upper panel) or anti-MAP kinase antibodies (lower panel)

Furthermore, S-adenosylhomocysteine (SAH), a product of methylation reactions, retains high affinity for methyltransferases and inhibits methylation reactions. ${ }^{6}$ Hence, D4R-mediated PLM activity could potentially affect the SAM/SAH ratio and cellular methylation status, exerting a broad influence throughout cellular metabolism.

The human dopamine D4 receptor gene (DRD4) displays a remarkable number of polymorphisms, some of which affect receptor protein structure. ${ }^{7-15}$ Among these, a 48-bp variable-number imperfect tandem repeat (VNTR) in exon III has generated particular interest, and the human DRD4 contains from 2 to 11 repeats, displaying a distinctive ethnic and geographic distribution pattern. ${ }^{12}$ The four-repeat variant (D4.4R) is predominant in most populations, with a world-wide allelic frequency of $64 \%$, followed by seven-repeat $(25 \%)$ and two-repeat variants (5\%). The VNTR encodes 16 -amino acid prolinerich segments in the third cytoplasmic loop of D4Rs that participate in SH3 domain-dependent linkage of signaling proteins to the receptor. ${ }^{14}$ A higher number of repeats implies that additional proteins can associate with the D4.7R, with the potential for more diverse signaling, although the additional protein interactions can restrict $\mathrm{D} 4 \mathrm{R}$ access to phospholipids. The $\mathrm{D} 4 \mathrm{R}$ is bound to postsynaptic scaffolding protein-95 (PSD-95) via SH3 domain-based binding, where it modulates $N$-methyl-Daspartate (NMDA) receptor function in a VNTRdependent manner, ${ }^{16}$ raising the possibility that the D4R may modulate synaptic function via the influence of dopamine-stimulated PLM on proteins sharing its membrane environment.

Modest differences in G protein/effector coupling efficiency $^{15,17-19}$ and receptor heterodimerization ${ }^{20,21}$ have been described among D4R VNTR variants, as well as greater inhibition of NMDA receptor function in the prefrontal cortex by the D4.7R. ${ }^{16}$ However, the functional importance of $\mathrm{D} 4 \mathrm{R}$ repeat number remains unclear and the influence of D4R VNTR on D4R-mediated PLM has not been previously investigated. 
In the current study, we examined the impact of D4R expression and dopamine exposure on D4R-mediated PLM and MS activity, as well as redox and methylation status, using stably transfected $\mathrm{CHO}$ cells expressing $\mathrm{D} 4.2 \mathrm{R}$, D4.4R, or D4.7R. Our findings reveal that the D4.7R has weaker maximal PLM activity compared to $\mathrm{D} 4.2 \mathrm{R}$ and D4.4R. Furthermore, D4R expression suppresses MS activity and confers a previously unappreciated ability of dopamine to exert metabolic and epigenetic regulation, significantly expanding the D4R signaling repertoire.

\section{Materials and methods Materials}

Wild-type (WT) $\mathrm{CHO}$ cells and transfected $\mathrm{CHO}$ cells stably expressing D4 receptors $(250-350 \mathrm{fmol} / \mathrm{mg}$ protein) were kindly provided by Dr. Oliver Civelli and their ligand-binding properties have been previously described. ${ }^{15}$ All studies were conducted with cells from the first 15 passages. Using designations from Lichter et al. ${ }^{8}$, repeat sequences in the receptors were: D4.2R: $\alpha \zeta$; D4.4R: $\alpha \beta \delta \zeta$; D4.7R: $\alpha \beta \eta \varepsilon \beta \varepsilon \zeta$; and each contained the duplicated 12 bp sequence in exon I. Dopamine, L-745870, and other chemicals were purchased from Sigma-Aldrich (St. Louis, $\mathrm{MO}$ ). Antibodies against phosphorylated and nonphosphorylated forms of mitogen-activate protein (MAP) kinase (catalog \# 4370 and 9102) were purchased from Cell Signaling Technologies Inc. (Beverly, MA).

\section{Thiol and thioester quantification}

Cells were treated as indicated for individual experiments, after which media were aspirated and cells were washed $2 \times$ with $1 \mathrm{~mL}$ of ice-cold Hanks' balanced salt solution (HBSS). HBSS was aspirated from the cells and $0.3 \mathrm{~mL}$ ice-cold $\mathrm{dH}_{2} \mathrm{O}$ was added to each well. The cell suspension was sonicated for $15 \mathrm{~s}$ on ice, and $100 \mu \mathrm{L}$ of sonicate was removed and used to determine protein content. Two hundred microliters of the remaining sonicate was added to $50 \mu \mathrm{L}$ of $0.4 \mathrm{~N}$ perchloric acid. Sonicates were blown with nitrogen and spun at 13,000 RPM for $60 \mathrm{~min}$ to remove protein and cellular debris. One hundred microliters of sample was added to a conical micro autosampler vial, blown with nitrogen, capped, and kept at $4{ }^{\circ} \mathrm{C}$ in the autosampler cooling tray (ESA model 542). Ten microliters of sample was injected into an ESA CoulArray high-performance liquid chromatographic system with a BDD analytical cell (model 5040) electrochemical detector at an operating potential of $1500 \mathrm{mV}$, equipped with an Agilent Eclipse XDB-C8 $\left(3 \times 150 \mathrm{~mm}^{2}, 3.5 \mu \mathrm{m}\right)$ reverse-phase C8 column. A dual mobile phase gradient elution was used, consisting of mobile phase (A) containing sodium phosphate $25 \mathrm{mM}$ and 1-octanesulfonic acid $2.1 \mathrm{mM}$, adjusted to $\mathrm{pH} 2.65$ with phosphoric acid, with the second mobile phase (B) containing $50 \%$ acetonitrile. The system was run at a flow rate of $0.6 \mathrm{~mL} / \mathrm{min}$ at ambient temperature with the following gradients: 0-9 min, 0\% B; 9-38 min, 30\% B. Post run, the system was cleaned with $100 \%$ B for $4 \mathrm{~min}$, the cell was cleaned for $3 \mathrm{~min}$ at an operating potential of $1900 \mathrm{mV}$, and the system was equilibrated at $0 \% \mathrm{~B}$ for 8 min prior to the next run. Peak area analysis was provided by CoulArray 3.06 software (ESA, Chelmsford, $\mathrm{MA})$, based on standard curves generated for each compound and sample metabolite values were normalized to protein content.

\section{MS assay}

After drug treatment, cells were scraped, pelleted, and frozen at $-80^{\circ} \mathrm{C}$ prior to assay. Approximately $10^{8}$ cells were resuspended in $1 \mathrm{~mL}$ of $100 \mathrm{mM}$ phosphate buffer, $\mathrm{pH} 7.4$, containing $0.25 \mathrm{M}$ sucrose. Cell membranes were disrupted by sonication on ice and the homogenate centrifuged at $4{ }^{\circ} \mathrm{C}$. Enzyme assays were performed under anaerobic conditions, as previously described ${ }^{18}$. The reaction mixture contained $100 \mathrm{mM}$ potassium phosphate, $\mathrm{pH} 7.2,500 \mu \mathrm{M}$ HCY, $152 \mu \mathrm{M}$ SAM, $2 \mathrm{mM}$ titanium citrate, $250 \mu \mathrm{M}(6 R, S)-5-\left[{ }^{14} C\right]$ methyltetrahydrofolate, and enzyme in a final volume of $1 \mathrm{~mL}$. Different cobalamins were added at a final concentration of $10 \mu \mathrm{M}$. The reaction was initiated by the addition of methylfolate, incubated for $60 \mathrm{~min}$ at $37^{\circ} \mathrm{C}$, and terminated by heating at $98^{\circ} \mathrm{C}$ for $2 \mathrm{~min}$. Radiolabeled methionine was separated on a Dowex 1-X8 column, which was eluted with $2 \mathrm{~mL}$ of water. Control assays, in which sample enzyme was omitted, served as blanks.

\section{DNA methylation analysis}

DNA was isolated using the DNeasy Blood \& Tissue Kit (Qiagen) according to the provided protocol. Isolated DNA was quantified using an ND-1000 NanoDrop spectrophotometer. Isolated DNA was adjusted to a concentration of $50 \mathrm{ng} / \mathrm{mL}$ and $100 \mathrm{ng}$ of DNA was used for each assay. Global DNA methylation was assayed using the MethylFlash ${ }^{\mathrm{TM}}$ Methylated DNA Quantification Kit (Epigentek).

\section{PLM measurement}

$\mathrm{CHO}$ cells were grown in six-well plates in $\alpha$-MEM supplemented with $10 \%$ fetal bovine serum and $1 \%$ penicillin/streptomycin/fungizone. After a wash with HBSS, cells were incubated at $37^{\circ} \mathrm{C}$ for $30 \mathrm{~min}$ or the desired time in $600 \mu \mathrm{L}$ of Hank's solution containing $1 \mu \mathrm{Ci} / \mathrm{mL}\left[{ }^{14} \mathrm{C}\right]$ formate or $\left[{ }^{3} \mathrm{H}\right.$-methyl $]$ methionine, with or without drugs as desired. The reaction was terminated by an initial wash with ice-cold unlabeled HBSS, followed by $500 \mu \mathrm{L}$ ice-cold $10 \%$ TCA. After scraping, cells were transferred to an Eppendorf tube, sonicated, and an aliquot was removed for protein assay. Following 
centrifugation, the pellet was dispersed in $1.5 \mathrm{~mL}$ of $2 \mathrm{~N}$ $\mathrm{HCl} / \mathrm{MeOH} / \mathrm{CHCl}_{3}$ (1:3:6), vortexed, and allowed to separate. The lower $\mathrm{CHCl}_{3}$ layer was washed twice with $400 \mu \mathrm{L}$ of $0.1 \mathrm{~N} \mathrm{KCl}$ in $50 \% \mathrm{MeOH}$ and an aliquot counted for radioactivity after evaporation.

\section{Western blot}

After treatment, $50 \mu \mathrm{g}$ of cell lysate was subjected to electrophoresis on a $10-20 \%$ sodium dodecyl sulfatepolyacrylamide gel electrophoresis gel. Separated proteins were transferred to a nitrocellulose membrane. Blots were rinsed, blocked, and incubated with primary antibody for $2 \mathrm{~h}$ at room temperature with shaking. The blot was then washed and incubated with goat anti-rabbit peroxidase for $1 \mathrm{~h}$, washed, incubated with a chemiluminescence reagent for $1 \mathrm{~min}$ at room temperature, and then exposed to autoradiograph film for $10 \mathrm{~s}$.

\section{Statistical analyses}

Figures reflect mean values $( \pm$ SEM) from representative, replicated experiments. Number of samples is specified in figure legends. Prism 6 (GraphPad Software, San Diego, CA) was utilized for curve fitting and other data analyses. Student's $t$ test (two-sided) was used for statistical evaluation of significant differences, with $p \leq 0.05$ as a threshold value.

\section{Results}

\section{Dopamine-stimulated PLM}

Dopamine-stimulated PLM was measured using a $\left[{ }^{14} \mathrm{C}\right]$ formate-based assay ${ }^{1}$ that radiolabels the methyl group of 5-methylTHF, allowing quantitation of D4R-dependent methylation of phosphatidylethanolamine (PE). Dopamine significantly increased folate-dependent PLM in $\mathrm{CHO}$ cells expressing the D4.4R (Fig. 1b). Consistent with D4 receptor involvement, the dopamine-induced increase was blocked by the highly selective D4R antagonist L745870 and by clozapine, a moderately selective D4 receptor antagonist. In contrast, when D4R-independent PLM was measured using $\left[{ }^{3} \mathrm{H}\right.$-methyl]-methionine, no effect of dopamine was observed (data not shown). These results confirm the ability of D4 receptor activation to selectively promote folate-dependent PLM in transfected $\mathrm{CHO}$ cells.

We then compared dopamine-stimulated PLM in dose-response studies with D4.2R-, D4.4R-, and D4.7Rexpressing $\mathrm{CHO}$ cells. Basal PLM activity was $\sim 2$-fold higher in cells expressing D4.2R and D4.4R, whereas D4.7R expression did not affect basal PLM (Fig. 1c). Maximal dopamine activation $(10 \mu \mathrm{M})$ produced a smaller PLM increase in D4.7R vs. D4.2R or D4.4R-expressing cells $(p<0.001)$, although the percent increase above basal $(350 \%)$ was similar for all three subtypes. $\mathrm{EC}_{50}$ (halfmaximal effective concentration) values for dopamine stimulation of PLM were $71 \pm 12,67 \pm 9$, and $0.82 \pm$ $0.14 \mathrm{nM}$ for $\mathrm{D} 4.2 \mathrm{R}, \mathrm{D} 4.4 \mathrm{R}$, and $\mathrm{D} 4.7 \mathrm{R}$, indicating that dopamine was significantly more potent $(p<0.001)$, albeit less efficacious, at stimulating PLM via D4.7R. This result is in contrast to inhibition of cAMP formation, where the D4.7R response to dopamine was reported to be less potent but equally efficacious. ${ }^{16}$ Dopamine stimulation of MAP kinase phosphorylation, mediated by $G$ protein signaling, was similar for D4.2R, D4.4R, and D4.7R, further indicating that PLM is a signaling response that differentiates the D4.7R from D4.2R and D4.4 subtypes.

\section{MS activity}

We next compared the ability of dopamine to affect MS activity in control and D4R-transfected CHO cells, measured as the conversion of $\mathrm{HCY}$ to methionine. Basal MS activity decreased by $\sim 90 \%$ in all three D4R-transfected cell lines, as compared to WT CHO cells (Table 1),

Table 1 Methionine synthase activity in CHO cell homogenates after treatment of intact cells with dopamine or the D4R antagonist L-745870

\begin{tabular}{|c|c|c|c|}
\hline Cell type & Treatment & $\begin{array}{l}\text { MS activity } \\
\text { (pmol/min/mg) }\end{array}$ & \%WT basal \\
\hline \multirow[t]{4}{*}{ WT CHO } & Basal & $205 \pm 12$ & 100 \\
\hline & $\begin{array}{l}\text { Dopamine }(10 \mu \mathrm{M} \text {; } \\
30 \mathrm{~min})\end{array}$ & $208 \pm 18$ & 101 \\
\hline & $\begin{array}{l}\text { L-745870 (100 nM; } \\
60 \mathrm{~min})\end{array}$ & $201 \pm 7$ & 98 \\
\hline & $\begin{array}{l}\text { Dopamine + L- } \\
745870\end{array}$ & $216 \pm 15$ & 105 \\
\hline \multirow[t]{4}{*}{$\mathrm{D} 4.2 \mathrm{CHO}$} & Basal & $20.5 \pm 1.8^{a}$ & 10 \\
\hline & Dopamine & $38.5 \pm 3.3^{b}$ & 19 \\
\hline & L-745870 & $6.6 \pm 0.7^{b}$ & 3 \\
\hline & $\begin{array}{l}\text { Dopamine + L- } \\
745870\end{array}$ & $6.9 \pm 0.6^{b}$ & 3 \\
\hline \multirow[t]{4}{*}{$\mathrm{D} 4.4 \mathrm{CHO}$} & Basal & $21.2 \pm 0.5^{a}$ & 10 \\
\hline & Dopamine & $48.7 \pm 4.6^{b}$ & 24 \\
\hline & L-745870 & $6.5 \pm 0.5^{b}$ & 3 \\
\hline & $\begin{array}{l}\text { Dopamine }+ \text { L- } \\
745870\end{array}$ & $6.7 \pm 0.7^{b}$ & 3 \\
\hline \multirow[t]{4}{*}{$\mathrm{D} 4.7 \mathrm{CHO}$} & Basal & $18.8 \pm 0.8^{a}$ & 9 \\
\hline & Dopamine & $56.6 \pm 4.3^{b, c}$ & 28 \\
\hline & L-745870 & $6.4 \pm 0.3^{b}$ & 3 \\
\hline & $\begin{array}{l}\text { Dopamine }+ \text { L- } \\
745870\end{array}$ & $6.5 \pm 0.5^{b}$ & 3 \\
\hline
\end{tabular}

${ }^{\mathrm{a}}$ Significantly different from WT CHO basal $(p<0.001)$

${ }^{b}$ Significantly different from corresponding basal $(p<0.01)$

'Significantly different from D4.2 + dopamine $(p<0.05)$ 
consistent with D4R and MS interaction. A $30 \mathrm{~min}$ treatment of intact cells with dopamine $(10 \mu \mathrm{M})$ had no effect on subsequently measured MS activity in WT CHO cells, but significantly increased activity in each of the transfected cell lines, as previously reported for human neuroblastoma cells. ${ }^{2}$ Interestingly, the size of the dopamine-induced increase in MS activity was dependent on the number of $\mathrm{D} 4$ receptor repeats, amounting to 88 , 141 , and $177 \%$ above basal activity for D4.2R, D4.4R, and D4.7R, respectively.

Treatment of intact cells with the selective D4R antagonist L-745870 not only blocked dopamine stimulation of MS activity in D4R-expressing cells but also significantly decreased basal enzyme activity for all three receptor subtypes (Table 1). In contrast, addition of dopamine or L-745870 directly to the MS assay had no effect (data not shown).

Together, these results indicate that basal MS activity is suppressed by D4R expression, but dopamine treatment of D4R-expressing cells allows recovery of a portion of HCY-directed MS activity. Opposite effects of dopamine and L-745870 pretreatment suggests that the suppressive influence of D4R expression on MS activity depends on receptor conformation.

\section{Methionine cycle metabolites}

Since D4R-mediated PLM is dependent on MS and other methylation cycle enzymes, we hypothesized that D4R expression and stimulation might affect levels of methionine cycle metabolites. To test this possibility, we examined metabolite levels in $\mathrm{CHO}$ cells expressing D4.2R, D4.4R, and D4.7R, as compared to non-transfected WT CHO cells.

Consistent with its reduction of MS activity, D4R expression significantly decreased basal methionine levels in $\mathrm{CHO}$ cells by $53 \%, 51 \%$, and $53 \%$ in $\mathrm{D} 4.2 \mathrm{R}-$, D4.4R-, and D4.7R-expressing cells, respectively $(p<0.005)$ (Fig. 2a). Dopamine $(10 \mu \mathrm{M} ; 30 \mathrm{~min})$ had no significant effect on methionine levels, either in D4R-transfected or -nontransfected cells. Treatment with L-745870 (100 nM; $60 \mathrm{~min}$ ) non-significantly increased methionine in D4.4Rexpressing, but not in D4.2R- or D4.7R-expressing cells.

D4R expression significantly decreased basal SAM levels by $71 \%, 67 \%$, and $54 \%$ in D4.2R-, D4.4R-, and D4.7Rexpressing cells, respectively, with the decrease being significantly greater for D4.7R vs. D4.2R $(p<0.001)$ or D4.4R $(p<0.05)$ (Fig. 2b). Dopamine treatment increased SAM by $79 \%, 73 \%$, and $79 \%$, respectively, but had no effect in non-transfected cells. L-745870 blocked the effects of dopamine in all D4R-expressing cells and decreased the basal level of SAM in D4.7R-expressing cells, suggestive of constitutive receptor activity.

D4R expression decreased basal SAH levels by $65 \%$, $34 \%$, and $57 \%$ in D4.2R-, D4.4R-, and D4.7R-expressing cells, respectively, whereas dopamine stimulation decreased SAH levels by $65 \%, 81 \%$, and $41 \%$, respectively (Fig. 2c). Dopamine treatment increased the SAM/SAH ratio by 4.0-, 7.6-, and 3.9-fold in D4.2R-, D4.4R-, and D4.7R-expressing cells, respectively, but did not change the SAM/SAH ratio in non-transfected cells (Fig. 2e). L745870 decreased the SAM/SAH ratio in D4.7-expressing cells by $60 \%$.

D4R expression significantly decreased basal HCY levels in CHO cells by $44 \%$, and $65 \%$ in D4.2R and D4.7R $(p<$ 0.05 ), but the $39 \%$ decrease in D4.4R-expressing cells was not significant $(p=0.142)$ (Fig. $2 \mathrm{~d})$. Dopamine had no significant effect on HCY levels either in D4R-transfected or -non-transfected cells.

\section{GSH synthesis pathway metabolites}

Since transsulfuration of $\mathrm{HCY}$ to cysteine links the methionine cycle to GSH synthesis, we next examined the effect of D4R expression on metabolites in this redoxrelated pathway. D4.2R expression significantly decreased basal cysteine levels by $54 \%$, whereas decreases of 24 and $21 \%$ for $\mathrm{D} 4.4 \mathrm{R}$ and $\mathrm{D} 4.7 \mathrm{R}$, respectively, were not significant (Fig. 3a). The addition of dopamine did not affect cysteine levels in either WT or D4R-expressing cells.

Cystathionine is a key transsulfuration intermediate linking $\mathrm{HCy}$ to cysteine. D4R expression significantly decreased cystathionine levels by $56 \%, 56 \%$, and $65 \%$ for D4.2R, D4.4R, and D4.7R, respectively, and its level was unaffected by dopamine or L-745870 (Fig. 3b).

D4R expression significantly decreased basal GSH by $48 \%, 35 \%$, and $30 \%$ in D4.2R-, D4.4R-, and D4.7Rexpressing cells, respectively (Fig. 3c). Dopamine treatment increased intracellular GSH by $50 \%, 45 \%$, and $39 \%$ in D4.2R-, D4.4R-, and D4.7R-expressing cells, respectively, but did not affect GSH levels in non-transfected cells. L-745870 blocked the effects of dopamine in all D4R-expressing cells and decreased GSH significantly below basal level in D4.7R-expressing cells. D4R expression did not alter GSSG levels and dopamine treatment had little or no effect (Fig. 3d). Dopamine treatment increased the GSH/GSSG ratio by $69 \%, 79 \%$, and $90 \%$ in D4.2R-, D4.4R-, and D4.7R-expressing cells, respectively, but only D4.4R reached significance $(p<0.05)$ (Fig. 3e). Dopamine did not affect the GSH/GSSG ratio in nontransfected cells.

\section{Dopamine-stimulated changes in DNA methylation}

To investigate whether changes in the observed changes in SAM/SAH ratio translate into downstream changes in methylation, we measured global DNA methylation in D4R-transfected and -non-transfected $\mathrm{CHO}$ cells, with or without dopamine treatment. As indicated in Fig. 5, D4.2R, D4.4R, and D4.7R expression decreased basal global DNA methylation by $39 \%, 30 \%$, and $23 \%$, 

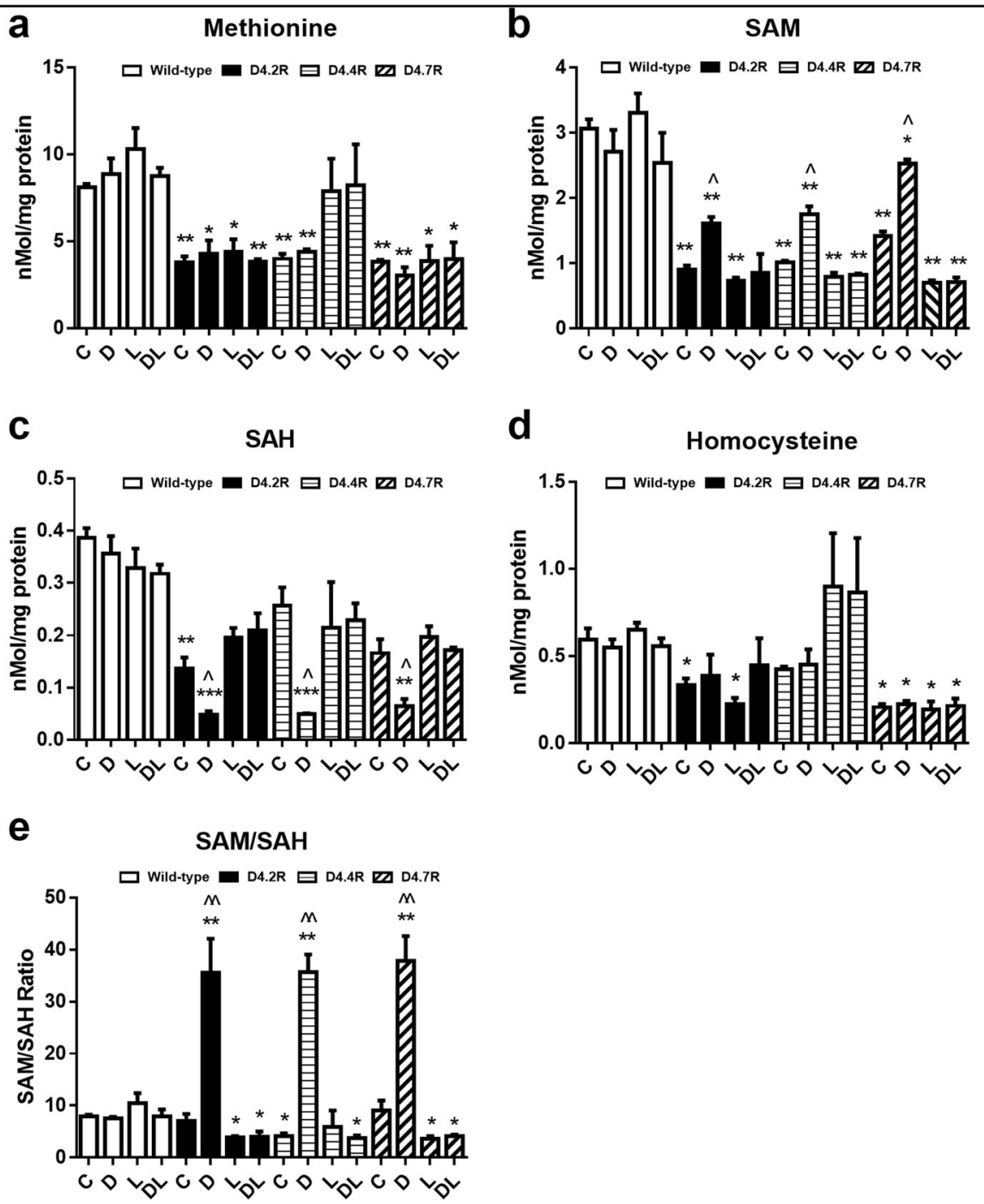

Fig. 2 D4R expression and dopamine affect methylation metabolites in CHO cells. Methylation metabolite levels (a Methionine, b SAM, c SAH, d Homocysteine, e SAM/SAH) were measured in wild-type (WT) CHO cells and CHO cells transfected to express D4.2R, D4.4R, and D4.7R. Cells were treated with dopamine $(10 \mu \mathrm{M} ; 30 \mathrm{~min})(\mathrm{D})$, or the D4R-selective antagonist L-745870 (100 nM; $60 \mathrm{~min})(\mathrm{L})$ or their combination $(\mathrm{DL})(n=3)$. Data are expressed as mean \pm SEM. Asterisks indicate significant differences from matched WT group $\left({ }^{*} p<0.05,{ }^{* *} p<0.01\right)$. $\wedge$ indicates significant difference from untreated control group (C) $(\wedge p<0.05, \wedge \wedge p<0.01)$

respectively. Consistent with the increases in SAM/SAH noted above, treatment with dopamine $(10 \mu \mathrm{M} ; 8 \mathrm{~h})$ increased global DNA methylation level by 137\%, 99\%, and $102 \%$ for D4.2R, D4.4R, and D4.7R variants, respectively. No significant differences were observed among different repeat variants in the extent of increased DNA methylation. The dopamine-induced increase in DNA methylation was blocked by L-745870, and dopamine had no effect on DNA methylation in non-transfected $\mathrm{CHO}$ cells. Thus, D4R expression decreases basal DNA methylation and confers DA responsiveness, consistent with its effect on MS activity and SAM/SAH.

\section{Discussion}

Following its initial cloning by Van Tol et al. ${ }^{22}$ in 1991, the $\mathrm{D} 4 \mathrm{R}$ received considerable attention for a possible role in schizophrenia, ${ }^{23-25}$ attention-deficit hyperactivity disorder (ADHD) ${ }^{26-30}$ novelty-seeking personality trait, ${ }^{31-33}$ drug abuse liability ${ }^{34-36}$, and longevity. ${ }^{37,38}$ In 1998, we first described the unique ability of the D4R to carry out folate-dependent methylation of membrane phospholipids, utilizing a conformationally active methionine residue at the inner membrane surface. ${ }^{1}$ D4R-mediated PLM requires some of the same enzymes as the classical methionine cycle (Fig. 1a), raising the possibility that it 

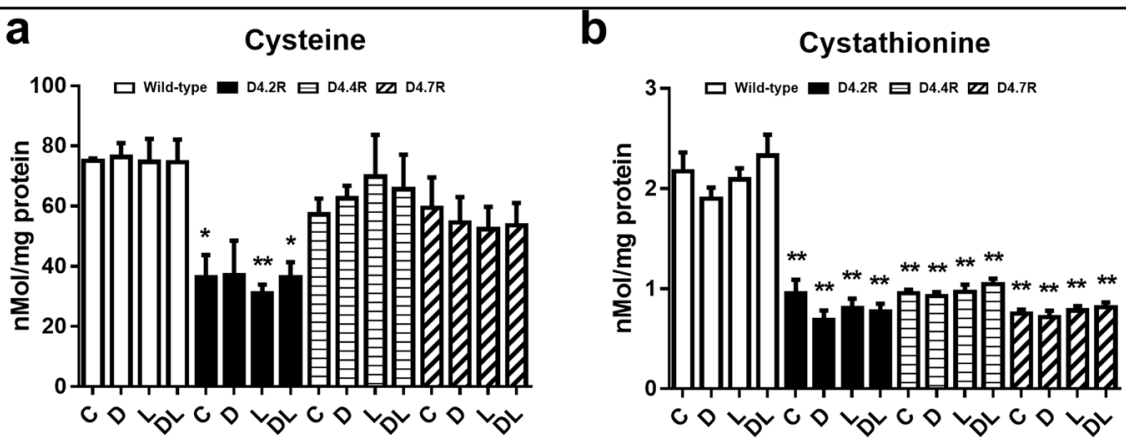

C

GSH

d

GSSG
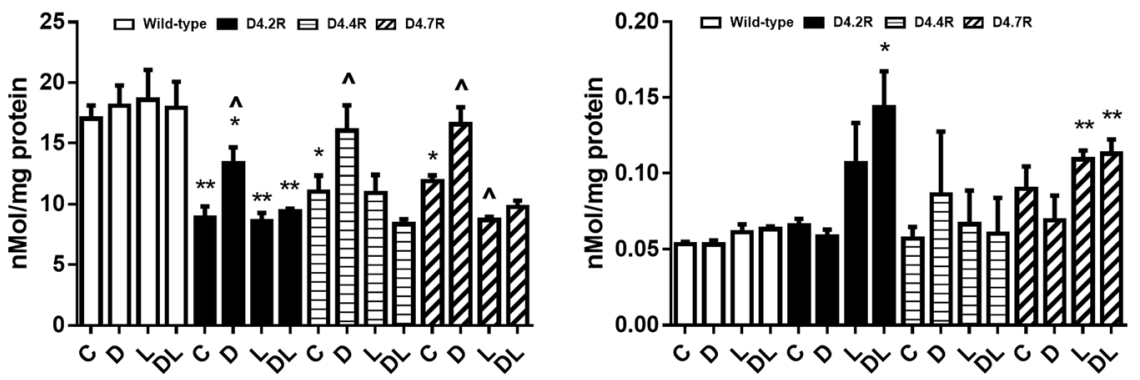

e

GSH/GSSG

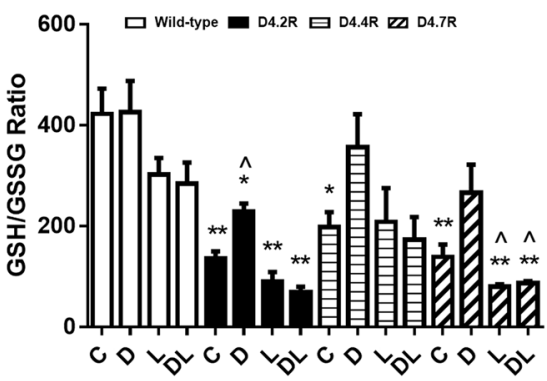

Fig. 3 D4R expression and dopamine alter redox-related thiol metabolites in CHO cells. Thiol metabolite levels (a Cysteine, b Cystathionine, c GSH, d GSSG, e GSH/GSSG) were measured in wild-type (WT) CHO cells and CHO cells transfected to express D4.2R, D4.4R, and D4.7R. Cells were treated with dopamine $(10 \mu \mathrm{M} ; 30 \mathrm{~min})(\mathrm{D})$, or the D4R-selective antagonist L-745870 (100 nM; $60 \mathrm{~min})(\mathrm{L})$ or their combination (DL) $(n=3)$. Data are expressed as mean \pm SEM. Asterisks indicate significant differences from matched WT group $\left({ }^{*} p<0.05, * * p<0.01\right)$. $\wedge$ indicates significant difference from untreated control group $(C)(\wedge p<0.05)$

might exert an influence over methionine cycle and interrelated GSH pathway metabolites. Indeed, our current results demonstrate a powerful suppressive influence of D4R expression on MS activity, accompanied by emergence of the ability of dopamine to augment MS activity, and increasing antioxidant and methylation status, including increased DNA methylation. Thus, D4R expression significantly expands the signaling repertoire of dopamine into metabolic and epigenetic domains.

Initial studies indicated that dopamine activates PLM via a conformational movement of transmembrane helix \#6 that exposes the active methionine residue (\#313 in the $\mathrm{D} 4.4 \mathrm{R})^{1}$, and more recent $\mathrm{x}$-ray crystallography studies subsequently confirmed this large agonist-induced rotational movement for the equivalent leucine residue in $\beta-2$ adrenergic receptors. ${ }^{39}$ Since it is the only G proteincoupled receptor (GPCR) with a methionine at this conformationally unique locus, dopamine-stimulated PLM activity appears to be a unique D4R signaling activity. By increasing the bulk and charge density of phospholipid headgroups, PLM alters plasma membrane biophysical properties, which can modulate the activity of membrane proteins sharing the D4R microenvironment. ${ }^{16,40,41}$ The molecular basis for lower PLM activity of the D4.7R may reflect its ability to bind a higher number of membrane proteins through $\mathrm{SH} 3$ domain interactions with its 
expanded repeats. Thus, a higher number of membrane proteins attached to the D4.7R could restrict its access to substrate phospholipids for methylation (Fig. 5a).

The recent demonstration of its binding to PSD- $95^{16}$ indicates that the D4R is well positioned for PLM to affect nearby proteins, as illustrated for glutamate receptors, potassium channels, and $\mathrm{Ca}^{2+}$-ATPase in Fig. 5b. In 2003, we first proposed that these actions might underlie

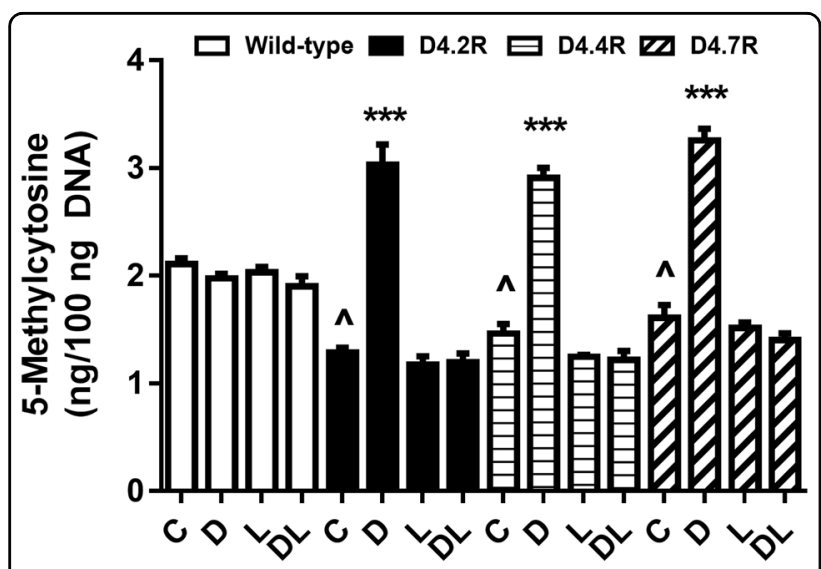

Fig. 4 Effects of D4R expression and dopamine on global DNA methylation in D4R-transfected CHO cells. Global DNA methylation was measured in wild-type (WT) $\mathrm{CHO}$ cells or $\mathrm{CHO}$ cells transfected with D4.2R, D4.4R, or D4.7R. Cells were untreated (C) or treated for $8 \mathrm{~h}$ with either dopamine $(\mathrm{D} ; 10 \mu \mathrm{M})$ or the $\mathrm{D} 4$-selective antagonist $\mathrm{L}$ $745870(\mathrm{~L} ; 100 \mathrm{nM})$ or both (DL) $(n=6)$. Asterisks indicate significant differences from matched WT group $\left({ }^{* * *} p<0.01\right)$. $\wedge$ indicates significant difference from untreated control group (C) $(\wedge p<0.05)$

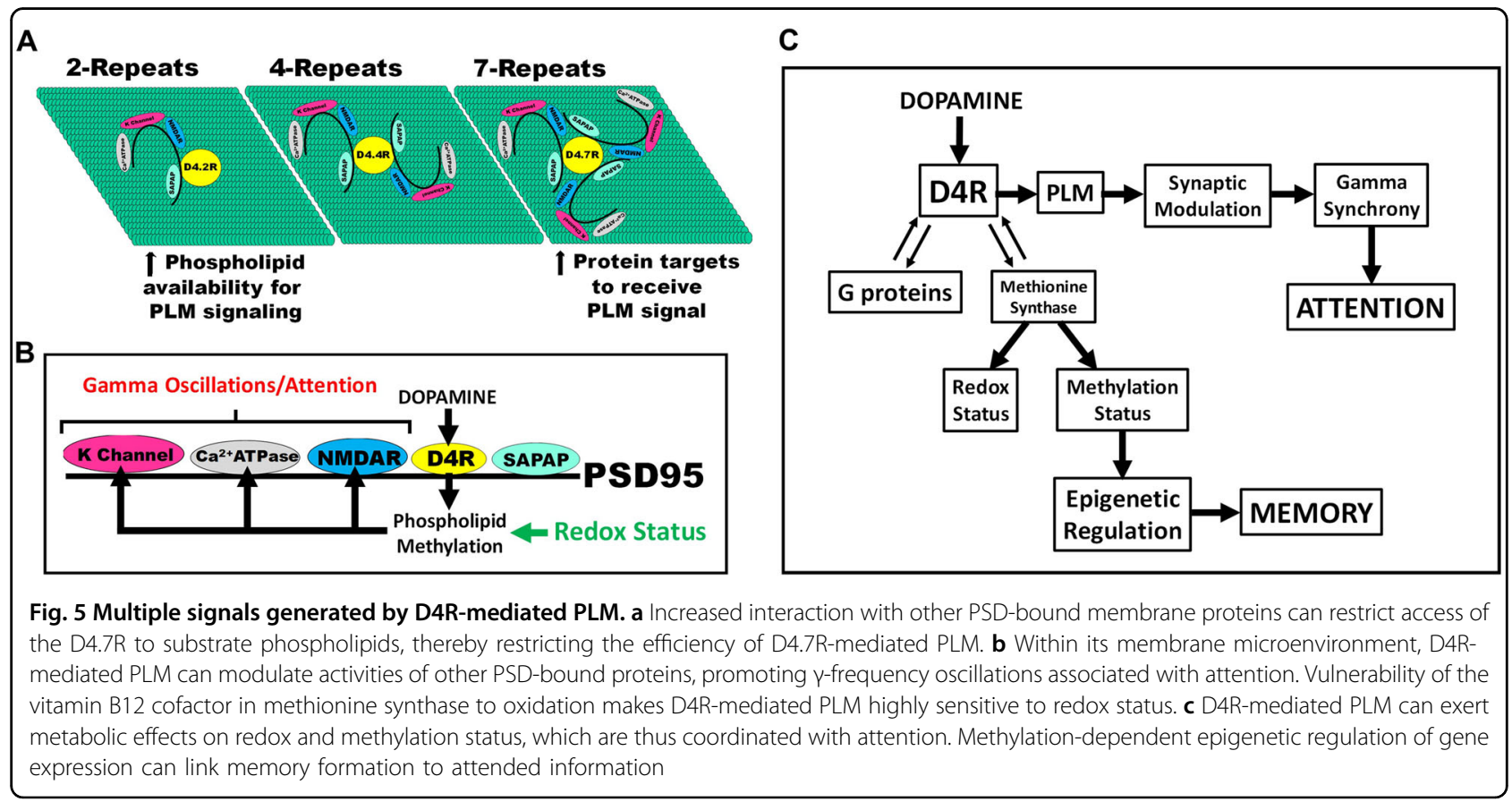

attention $^{42}$ and a number of studies have confirmed the ability of D4R activation to promote $\gamma$-frequency oscillations in parvalbumin-expressing GABAergic neural networks in association with attention. ${ }^{43-46}$ However, individuals with the D4.7R are at $\sim 4$-fold higher risk of $\mathrm{ADHD}^{27-31}$ and $\mathrm{D} 4.7 \mathrm{R}$ activation induces weaker suppression of GABAergic inhibitory network activity, as compared to D4.4R activation. ${ }^{16}$ Our finding that maximal PLM activity of the D4.7R is lower than D4.2R or D4.7R-associated ADHD risk.

D4R expression decreased basal methionine and SAM levels by more than $50 \%$, and dopamine exposure increased the SAM/SAH ratio by 3.9- to 7.6-fold (Fig. 2e). D4R expression therefore allows dopamine to exert profound effects on methylation status, reflected in part as increased DNA methylation (Fig. 4), while other methylation reactions can also be expected to respond to the dopamine-induced increase in SAM/SAH. Thus, D4Rs can exert an extraordinarily broad influence over cellular metabolism, including epigenetic regulation of gene expression, consistent with the recent demonstration that changes in PLM activity significantly alter histone methylation. ${ }^{47}$ As illustrated in Fig. 5c, the metabolic effects of D4R activation provide a link between attentionrelated $\gamma$-frequency synchronization and epigenetic memory formation, representing a potential mechanism for attention-driven learning.

Recognition of the ability of D4R expression and PLM activation to modulate MS activity, GSH levels, the SAM/ $\mathrm{SAH}$ ratio, and DNA methylation has potential D4.4R activity (Fig. 1c) provides a possible explanation for

\section{C}


implications for the clinical management of schizophrenia, ADHD, autism, and other neuropsychiatric disorders. It remarkably integrates multiple theories of schizophrenia etiology involving abnormal methylation and single-carbon metabolism, ${ }^{48-50}$ dopamine, ${ }^{51-53}$ and oxidative stress, ${ }^{54-56}$ while D4R modulation of NMDAR activity links these factors to glutamate-based theories. Importantly, oxidative stress and impaired methylation are amenable to metabolic interventions. For example, our previous finding that the level of methylcobalamin (methylB12; the active form of vitamin B12 supporting MS activity) is decreased by $\sim 60 \%$ in postmortem frontal cortex of schizophrenia and autism subjects ${ }^{57}$ strongly suggests that normalizing its brain levels may have therapeutic benefit. Several clinical studies have reported modest benefit of methylcobalamin in autism, ${ }^{58-60}$ but none have been conducted in schizophrenia. Adjunctive use of single-carbon folate derivatives, such as folinic acid or L-methylfolate, ${ }^{61-65}$ as well as $N$-acetylcysteine, ${ }^{66-68}$ which augments GSH levels, has been associated with clinical improvement. PE, the substrate for D4R-mediated PLM, is rich in $\Omega-3$ fatty acids, implying that a portion of the therapeutic benefits provided by fish oil supplements may be attributable to normalization of D4R-mediated PLM. While hyperhomocysteinemia is a useful indicator of low systemic MS activity, normal plasma levels do not necessarily exclude a brain deficit.

Our findings are subject to several important limitations. D4R expression and activation in $\mathrm{CHO}$ cells might not necessarily reflect the responses occurring in neuronal cells or within the postsynaptic density environment. The metabolic effects we observed might be dependent on the level of D4R expression, which was relatively high in the $\mathrm{CHO}$ cell model we employed. While changes in global DNA methylation strongly suggest D4R-mediated epigenetic effects, follow-up studies of gene expression are required to characterize effects on specific genes.

In summary, D4R expression decreases MS-dependent methylation of $\mathrm{HCY}$, affecting levels of key methylation and redox metabolites, while enabling an influence of dopamine over methylation and redox status, including DNA methylation. These previously unreported D4R activities may be important in attention-related memory formation and their dysfunction may contribute to neurocognitive disorders. Optimization of metabolic factors promoting methylation may be a useful adjunctive treatment for these conditions.

\section{Acknowledgements}

We would like to thank Dr. Oliver Civelli for generously providing the D4 receptor-expressing cell lines used in this study.

\section{Author details}

'Department of Neurology and the F.M. Kirby Neurobiology Center, Boston Children's Hospital, Boston, MA 02115, USA. ${ }^{2}$ Department of Food Science and Nutrition, College of Agricultural and Marine Sciences, Sultan Qaboos
University, Muscat 123, Oman. ${ }^{3}$ Department of Pharmaceutical Sciences, Nova Southeastern University, Fort Lauderdale, FL 33328, USA. ${ }^{4}$ Department of STEM, Regis College, Weston, MA 02493, USA

Conflict of interest

The authors declare that they have no conflict of interest.

\section{Publisher's note}

Springer Nature remains neutral with regard to jurisdictional claims in published maps and institutional affiliations.

Received: 14 February 2019 Revised: 13 October 2019 Accepted: 20 October 2019

Published online: 12 November 2019

\section{References}

1. Sharma, A. et al. D4 dopamine receptor-mediated phospholipid methylation and its implications for mental illnesses such as schizophrenia. Mol. Psychiatry 4, 235-246 (1999).

2. Waly, M. et al. Activation of methionine synthase by insulin-like growth factor1 and dopamine: a target for neurodevelopmental toxins and thimerosal. Mol. Psychiatry 9, 358-370 (2004).

3. Zhao, R. et al. Relationship between dopamine-stimulated phospholipid methylation and the single-carbon folate pathway. J. Neurochem. 78, 788-796 (2001).

4. Sharma, A., Waly, M. \& Deth, R. C. Protein kinase C regulates dopamine D4 receptor-mediated phospholipid methylation. Eur. J. Pharm. 427, 83-90 (2001).

5. Koutmos, M., Datta, S., Pattriidge, K. A., Smith, J. L. \& Matthews, R. G. Insights into the reactivation of cobalamin-dependent methionine synthase. Proc. Natl Acad. Sci. USA 106, 18527-18532 (2009).

6. Kennedy, B. P. et al. Elevated S-adenosylhomocysteine in Alzheimer brain: influence on methyltransferases and cognitive function. J. Neural Transm. (Vienna) 111, 547-567 (2004).

7. Van Tol, H. H. et al. Multiple dopamine D4 receptor variants in the human population. Nature 358, 149-152 (1992).

8. Lichter, J. B. et al. A hypervariable segment in the human dopamine receptor D4 (DRD4) gene. Hum. Mol. Genet. 2, 767-773 (1993).

9. Petronis, A., O'Hara, K., Barr, C. L., Kennedy, J. L. \& Van Tol, H. H. (G)n-mononucleotide polymorphism in the human D4 dopamine receptor (DRD4) gene. Hum. Genet. 93, 719 (1994).

10. Wang, E. et al. The genetic architecture of selection at the human dopamine receptor D4 (DRD4) gene locus. Am. J. Hum. Genet. 74, 931-944 (2004).

11. Livak, K. J., Rogers, J. \& Lichter, J. B. Variability of dopamine D4 receptor (DRD4) gene sequence within and among nonhuman primate species. Proc. Natl Acad. Sci. USA 92, 427-431 (1995).

12. Chang, F. M., Kidd, J. R., Livak, K. J., Pakstis, A. J. \& Kidd, K. K. The world-wide distribution of allele frequencies at the human dopamine D4 receptor locus. Hum. Genet. 98, 91-101 (1996).

13. Ding, Y. C. et al. Evidence of positive selection acting at the human dopamine receptor D4 gene locus. Proc. Natl Acad. Sci. USA 99, 309-314 (2002).

14. Oldenhof, J. et al. SH3 binding domains in the dopamine D4 receptor. Biochemistry 37, 15726-15736 (1998).

15. Asghari, V. et al. Modulation of intracellular cyclic AMP levels by different human dopamine D4 receptor variants. J. Neurochem. 65, 1157-1165 (1995).

16. Qin, L. et al. The ADHD-linked human dopamine D4 receptor variant D4.7 induces over-suppression of NMDA receptor function in prefrontal cortex. Neurobiol. Dis. 95, 194-203 (2016).

17. Wedemeyer, C. et al. Functional activation by central monoamines of human dopamine $\mathrm{D}(4)$ receptor polymorphic variants coupled to GIRK channels in Xenopus oocytes. Eur. J. Pharm. 562, 165-173 (2007).

18. Czermak, C., Lehofer, M., Liebmann, P. M. \& Traynor, J. $\left.{ }^{35} \mathrm{~S}\right] \mathrm{GTP}$ PammaS binding at the human dopamine D4 receptor variants hD4.2, hD4.4 and hD4.7 following stimulation by dopamine, epinephrine and norepinephrine. Eur. J. Pharm. 531, 20-24 (2006).

19. Kazmi, M. A., Snyder, L. A., Cypess, A. M., Graber, S. G. \& Sakmar, T. P. Selective reconstitution of human D4 dopamine receptor variants with Gi alpha subtypes. Biochemistry 39, 3734-3744 (2000). 
20. Van Craenenbroeck, K. et al. Dopamine D4 receptor oligomerization-contribution to receptor biogenesis. FEBS J. 278, 1333-1344 (2011).

21. Sánchez-Soto, M. et al. Revisiting the functional role of dopamine D4 receptor gene polymorphisms: heteromerization-dependent gain of function of the D4.7 receptor variant. Mol. Neurobiol. 56, 4778-4785 (2019).

22. Van Tol, H. H. et al. Cloning of the gene for a human dopamine D4 receptor with high affinity for the antipsychotic clozapine. Nature 350, 610-614 (1991).

23. Rondou, P., Haegeman, G. \& Van Craenenbroeck, K. The dopamine D4 receptor: biochemical and signalling properties. Cell Mol. Life Sci. 67, 1971-1986 (2010).

24. Kordi-Tamandani, D. M., Sahranavard, R. \& Torkamanzehi, A. Analysis of association between dopamine receptor genes' methylation and their expression profile with the risk of schizophrenia. Psychiatr. Genet. 23, 183-187 (2013)

25. Cheng, J. et al. Male-specific association between dopamine receptor D4 gene methylation and schizophrenia. PLOS ONE 9, e89128 (2014).

26. LaHoste, G. J. et al. Dopamine D4 receptor gene polymorphism is associated with attention deficit hyperactivity disorder. Mol. Psychiatry 1, 121-124 (1996).

27. McCracken, J. T. et al. Evidence for linkage of a tandem duplication polymorphism upstream of the dopamine D4 receptor gene (DRD4) with attention deficit hyperactivity disorder (ADHD). Mol. Psychiatry 5, 531-536 (2000).

28. Faraone, S. V., Doyle, A. E., Mick, E. \& Biederman, J. Meta-analysis of the association between the 7-repeat allele of the dopamine $D(4)$ receptor gene and attention deficit hyperactivity disorder. Am. J. Psychiatry 158, 1052-1057 (2001).

29. Gornick, M. C. et al. Association of the dopamine receptor D4 (DRD4) gene 7repeat allele with children with attention-deficit/hyperactivity disorder (ADHD): an update. Am. J. Med. Genet. B 144B, 379-382 (2007).

30. Gizer, I. R., Ficks, C. \& Waldman, I. D. Candidate gene studies of ADHD: a metaanalytic review. Hum. Genet. 126, 51-90 (2009).

31. Benjamin, J. et al. Population and familial association between the D4 dopamine receptor gene and measures of novelty seeking. Nat. Genet. 12, 81-84 (1996).

32. Ebstein, R. P. et al. Dopamine D4 receptor (D4DR) exon III polymorphism associated with the human personality trait of novelty seeking. Nat. Genet. 12, 78-80 (1996).

33. Schinka, J. A., Letsch, E. A. \& Crawford, F. C. DRD4 and novelty seeking: results of meta-analyses. Am. J. Med. Genet. 114, 643-648 (2002).

34. George, S. R., Cheng, R., Nguyen, T., Israel, Y. \& O'Dowd, B. F. Polymorphisms of the D4 dopamine receptor alleles in chronic alcoholism. Biochem. Biophys. Res. Commun. 196, 107-114 (1993).

35. Li, T. et al. Association analysis of the DRD4 and COMT genes in methamphetamine abuse. Am. J. Med. Genet. B 129B, 120-124 (2004).

36. Laucht, M., Becker, K., El-Faddagh, M., Hohm, E. \& Schmidt, M. H. Association of the DRD4 exon III polymorphism with smoking in fifteen-year-olds: a mediating role for novelty seeking? J. Am. Acad. Child Adolesc. Psychiatry 44, 477-484 (2005).

37. Grady, D. L. et al. DRD4 genotype predicts longevity in mouse and human. J. Neurosci. 33, 286-291 (2013).

38. Volkow, N. D. et al. Association between dopamine D4 receptor polymorphism and age related changes in brain glucose metabolism. PLOS ONE $\mathbf{8}$, e63492 (2013)

39. Gregorio, G. G. et al. Single-molecule analysis of ligand efficacy in $\beta 2 A R-G-$ protein activation. Nature 547, 68-73 (2017).

40. Kuznetsova, A. Y. \& Deth, R. C. A model for modulation of neuronal synchronization by D4 dopamine receptor-mediated phospholipid methylation. J. Comput. Neurosci. 24, 314-329 (2008).

41. Hirata, F. \& Axelrod, J. Enzymatic methylation of phosphatidylethanolamine increases erythrocyte membrane fluidity. Nature 275, 219-220 (1978).

42. Deth, R. C. Molecular Origins of Attention: The Dopamine-Folate Connection (Kluwer Academic Publishers, Boston/Dordrecht/London, 2003).

43. Andersson, R. H. et al. Neuregulin and dopamine modulation of hippocampal gamma oscillations is dependent on dopamine D4 receptors. Proc. Natl Acad. Sci. USA 109, 13118-13123 (2012).
44. Andersson, R., Johnston, A. \& Fisahn, A. Dopamine D4 receptor activation increases hippocampal gamma oscillations by enhancing synchronization of fast-spiking interneurons. PLOS ONE 7, e40906 (2012).

45. Kocsis, B., Lee, P. \& Deth, R. Enhancement of gamma activity after selective activation of dopamine D4 receptors in freely moving rats and in a neurodevelopmental model of schizophrenia. Brain Struct. Funct. 219, 2173-2180 (2014).

46. Zhong, P. \& Yan, Z. Distinct physiological effects of dopamine D4 receptors on prefrontal cortical pyramidal neurons and fast-spiking interneurons. Cereb. Cortex 26, 180-191 (2016).

47. Ye, C., Sutter, B. M., Wang, Y., Kuang, Z. \& Tu, B. P. A metabolic function for phospholipid and histone methylation. Mol. Cell 66, 180-193 (2017).

48. Pollin, W., Cardon, P. V. Jr \& Kety, S. S. Effects of amino acid feedings in schizophrenic patients treated with iproniazid. Science 133, 104-510. (1961).

49. Park, L. C., Baldessarini, R. J. \& Kety, S. S. Methionine effects on chronic schizophrenics: patients treated with monoamine oxidase inhibitors. Arch. Gen. Psychiatry 12, 346-351 (1965).

50. Regland, B. Schizophrenia and single-carbon metabolism. Prog. Neuropsychopharmacol. Biol. Psychiatry 29, 1124-1132 (2005).

51. Meltzer, H. Y. \& Stahl, S. M. The dopamine hypothesis of schizophrenia: a review. Schizophr. Bull. 2, 19-76 (1976).

52. Carlsson, A. Does dopamine play a role in schizophrenia? Psychol. Med. 7, 583-597 (1977).

53. Carlsson, A. The current status of the dopamine hypothesis of schizophrenia Neuropsychopharmacology 1, 179-186 (1988).

54. Reddy, R. D. \& Yao, J. K. Free radical pathology in schizophrenia: a review. Prostaglandins Leukot. Essent. Fatty. Acids 55, 33-43 (1996).

55. Mahadik, S. P. \& Scheffer, R. E. Oxidative injury and potential use of antioxidants in schizophrenia. Prostaglandins Leukot. Essent. Fatty. Acids 55, 45-54 (1996).

56. Steullet, P. et al. Oxidative stress-driven parvalbumin interneuron impairment as a common mechanism in models of schizophrenia. Mol. Psychiatry 22, 936-943 (2017).

57. Zhang, Y. et al. Decreased brain levels of vitamin B12 in aging, autism and schizophrenia. PLOS ONE 11, e0146797 (2016).

58. Frye, R. E. et al. Effectiveness of methylcobalamin and folinic acid treatment on adaptive behavior in children with autistic disorder is related to glutathione redox status. Autism Res. Treat. 2013, 609705 (2013).

59. Hendren, R. L. et al. Randomized, placebo-controlled trial of methyl B12 for children with autism. J. Child Adolesc. Psychopharmacol. 26, 774-783 (2016).

60. Delhey, L. M. et al. Comparison of treatment for metabolic disorders associated with autism: reanalysis of three clinical trials. Front. Neurosci. 12, 19 (2018).

61. Frye, R. E. et al. Folinic acid improves verbal communication in children with autism and language impairment: a randomized double-blind placebo-controlled trial. Mol. Psychiatry 23, 247-256 (2018).

62. Ramaekers, V. T., Sequeira, J. M. \& Quadros, E. V. The basis for folinic acid treatment in neuro-psychiatric disorders. Biochimie 126, 79-90 (2016).

63. Ramaekers, V. T. et al. Folinic acid treatment for schizophrenia associated with folate receptor autoantibodies. Mol. Genet. Metab. 113, 307-314 (2014).

64. Roffman, J. L. N. F. et al. Biochemical, physiological and clinical effects of Imethylfolate in schizophrenia: a randomized controlled trial. Mol. Psychiatry 23, 316-322 (2018)

65. Sakuma, K. et al. Folic acid/methylfolate for the treatment of psychopathology in schizophrenia: a systematic review and meta-analysis. Psychopharmacology (Berl.) 235, 2303-2314 (2018).

66. Sepehrmanesh, Z., Heidary, M., Akasheh, N., Akbari, H. \& Heidary, M. Therapeutic effect of adjunctive $\mathrm{N}$-acetyl cysteine (NAC) on symptoms of chronic schizophrenia: a double-blind, randomized clinical trial. Prog. Neuropsychopharmacol. Biol. Psychiatry 82, 289-296 (2018).

67. Breier, A. et al. Effects of 12-month, double-blind $\mathrm{N}$-acetyl cysteine on symptoms, cognition and brain morphology in early phase schizophrenia spectrum disorders. Schizophr. Res. 199, 395-402 (2018).

68. Yang, Y. S. et al. N-acetylcysteine improves EEG measures of auditory deviance detection and neural synchronization in schizophrenia: a randomized, controlled pilot study. Schizophr. Res. 208, 479-480 (2019). 